\title{
Effects of Habitual Smoking on Cardiorespiratory Responses to Sub-maximal Exercise
}

\author{
Yoshio Kobayashi ${ }^{1)}$, Toshiko Takeuchi ${ }^{1)}$, Teruo Hosoi ${ }^{1)}$ and Jack A. Loeppky ${ }^{2)}$ \\ 1) The Laboratory for Health and Human Performance, School of Arts and Sciences, Chukyo University \\ 2) Cardiology Section, VA Medical Center, Albuquerque, NM 87108, USA
}

\begin{abstract}
The effects of habitual cigarette smoking on cardiorespiratory responses to sub-maximal and maximal work were evaluated in nine adult nonsmokers and nine smokers with a mean age of $33 \mathrm{yr}$. A maximal treadmill test was followed by three tests at 45,60 and $75 \%$ of each subject's $\dot{\mathrm{V}}_{2}$ max. Compared to nonsmokers, the habitual smokers had a non-significantly lower $\dot{\mathrm{V}}_{2}$ max in $\mathrm{L} / \mathrm{min}$ and per lean body mass ( 9 and $6 \%$, respectively), but had higher $\%$ fat $(\mathrm{p}<0.01)$, resulting in a significantly lower $\dot{\mathrm{V}}_{2}$ max per $\mathrm{kg}$ body wt $(13 \%, \mathrm{p}<0.03)$. Maximal exercise ventilation $\left(\dot{\mathrm{V}}_{\mathrm{E}}\right)$ was $16 \%$ lower in smokers. During sub-maximal work at equivalent exercise stress levels in the two groups, the $\dot{\mathrm{V}}_{\mathrm{E}} / \dot{\mathrm{VO}}_{2}$ ratio was higher in smokers by an average of $11 \%$ because $\dot{\mathrm{VO}}_{2}$ was lower and the respiratory exchange ratio values were significantly elevated in smokers at $75 \%$ of $\dot{\mathrm{VO}}_{2}$ max. Blood lactate concentrations in smokers were higher as workloads increased and $\mathrm{O}_{2}$ pulse $\left(\mathrm{V}_{2} / \mathrm{HR}\right)$ was significantly lower throughout, indicating reduced $\mathrm{O}_{2}$ extraction, probably due to carbon monoxide. The resting HR was significantly higher in smokers and the HR recovery following all three submaximal exercises was significantly slower in smokers. These results show that detrimental cardiorespiratory effects of chronic cigarette smoking in apparently healthy individuals are evident at moderate exercise levels as reduced gas exchange efficiency in lungs and muscles. J Physiol Anthropol Appl Human Sci 23

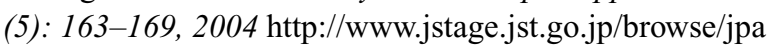

Keywords: carboxyhemoglobin, exercise responses, habitual smoking, $\mathrm{O}_{2}$ extraction, $\dot{\mathrm{V}} \mathrm{O}_{2} \max (\mathrm{ml} / \mathrm{min} / \mathrm{kg})$, ventilatory efficiency

\section{Introduction}

Cigarette smoking remains a prominent international health issue in adults. Long-term cigarette smoking is associated with the increased risks of most chronic diseases, including lung cancer, obstructive pulmonary disease, coronary heart disease, hypertension and stroke (US Public Health Service, 1983,
1984, 1988). Smoking also affects work performance, especially endurance exercise. Reports show that aerobic $\left(\mathrm{V}_{2} \max \right)$ and anaerobic power are reduced in smokers of various ages (Dressendorfer et al., 1983; Chatterjee et al., 1987; Fukuba et al., 1993; Knapik et al., 1993; Louie 2001; Bernaards et al., 2003). Hirsch et al. (1985) reported that $\dot{\mathrm{VO}}_{2} \max$ and anaerobic threshold were acutely reduced in apparently healthy adult smokers immediately after smoking, as compared to five hours after smoking, presumably because of elevated carbon monoxide and nicotine. In contrast to these studies, others have reported no difference in $\dot{\mathrm{VO}}_{2}$ max between the smokers and nonsmokers in populations of sportsmen (Morton and Holmik, 1985) and young workers (Maksud and Baron, 1980).

Smoking is an addiction that has become incorporated into society over the last few centuries. It has overtly and covertly influenced human life expectancies and health norms and, as such, has become incorporated into the health and life expectancy statistics of most nations. Although smoking results in adaptations to certain of its ingredients, notably carbon monoxide, countless studies have shown that it exerts a negative influence on life expectancy and potentiates existing health problems, especially cardiorespiratory illnesses. In spite of this, many smokers do not exhibit obvious health and exercise deficiencies, even though the fact of their smoking indicates a lack of concern for healthy living, including weight control. These "healthy" smokers may not experience exercise limitations because they do not exist or because they do not exercise at sufficient intensities to notice. However, they may show subtle differences in submaximal exercise responses when compared with similar nonsmokers. Differences during submaximal exercise may show underlying limitations due to smoking that may be worsened if smoking continues.

One reason for inconsistent results among studies comparing work capacity between the smokers and nonsmokers may be that some physiological variables determining $\dot{\mathrm{VO}}_{2} \max$ are genetically determined (Park et al., 1988 ) and may interact with the smoking effects. In addition, it is well documented that smokers have tendencies to be less 
physically active than nonsmokers (Blair et al., 1985) and tend to be heavier. Exercise responses between the smokers and nonsmokers should ideally be compared in subjects of similar age, exercise habits, body composition and $\dot{\mathrm{VO}}_{2} \max$ in order to eliminate these influences, but these subject groups are difficult to assemble, resulting in few well-controlled studies where smoking is the only variable.

The purpose of this study was to determine whether the habitual smoking altered responses to submaximal exercise. The comparison of the cardiorespiratory responses between two groups of generally similar and apparently healthy adult smokers and nonsmokers has been done during treadmill exercises ranging from low to high intensity.

\section{Methods}

Subjects: 18 healthy males volunteered to participant in this experiment. Nine of them were smokers and the other nine were nonsmokers. Because the nonsmokers were more prevalent than the smokers, the latter were recruited first and then the nonsmokers equal to that number were chosen. The Committee for Human Experiments, Chukyo University, approved the study and all subjects gave informed consent. All subjects were employed in the same law enforcement department for a number of years and regular physical exercise was similar for them and primarily limited to that required by employment. The nine smokers had smoked an average of 15 cigarettes/day for at least five years prior to the study.

Experimental design and test procedures: The subjects' baseline information and resting and maximal exercise data were obtained first. Then the cardiorespiratory responses to three levels of treadmill exercise were measured. The lowest level was equivalent to more strenuous daily living tasks (Dauncey, 1990). All measurements and the four exercise sessions were conducted in the morning, with the subjects having abstained from smoking and eating overnight prior to each session. The subjects' age, weight, height and other measurements are shown in Tables 1 and 2. Body density and percentage of body fat ( $\%$ fat) were determined by hydrostatic weighing (Brozek et al., 1963) on the day that $\dot{\mathrm{VO}}_{2} \max$ was measured; with residual lung volume estimated by closed circuit $\mathrm{O}_{2}$ dilution (Wilmore, 1969).

Measurements: Resting heart rate (HR) was obtained by ECG after $10 \mathrm{~min}$ of supine rest and systolic (SBP) and diastolic (DBP) blood pressures were measured by arm cuff with mercury sphygmomanometer. $\dot{\mathrm{VO}}_{2} \mathrm{max}$ was determined by an incremental test to voluntary exhaustion on a treadmill (MEDTRACK 65, Quinton Instruments, Seattle, WA, USA). A standard protocol (Froelicher et al., 1974) was used, beginning at $3.3 \mathrm{MPH}$ and $0 \%$ grade for $3 \mathrm{~min}$ and then increasing the grade by $5 \%$ every $3 \mathrm{~min}$. The gas exchange was recorded by an automated on-line gas analysis system (Oxycon Gamma, Mijnhardt, Bunnik, Netherlands) calibrated with known gas mixtures. The $\dot{\mathrm{VO}}_{2}$ max was taken to be either (a) the $\dot{\mathrm{VO}} \mathrm{O}_{2}$ value during the last minute prior to test termination due to exhaustion, if the highest value occurred in that minute, or (b) the value at an earlier interval if it subsequently declined. A respiratory exchange ratio (RER) value $>1.15$ was required to accept the $\dot{\mathrm{V}}_{2}$ max value.

Test procedures: The subjects completed the three submaximal exercise tests after the $\mathrm{V}_{2}$ max test, on three separate occasions, seven days apart. Upon reporting to the laboratory in the morning, electrodes were placed and the gas-collection mask was attached to the subject. After an initial 10-min rest period, while sitting, HR and blood pressures were obtained and venous blood drawn from an arm vein for hematocrit (Hct), hemoglobin concentration $(\mathrm{Hb})$ and carboxyhemoglobin (HbCO) determinations by spectrophotometer (CO-oximeter, IL, Milan, Italy).

The subject then began a 10 -min steady state treadmill exercise at 3.3 MPH at one of three workloads predicted from the prior $\dot{\mathrm{VO}}_{2} \max$ test to approximate 45,60 or $75 \%$ of his $\dot{\mathrm{VO}}_{2}$ max workload, the order being randomly assigned. The measurements obtained continuously during work were HR, $\dot{\mathrm{V}} \mathrm{O}_{2}, \dot{\mathrm{V} C O} \mathrm{O}_{2}, \mathrm{RER}$, minute ventilation $\left(\dot{\mathrm{V}}_{\mathrm{E}}\right)$, tidal volume $\left(\mathrm{V}_{\mathrm{T}}\right)$ and breathing rate $\left(f_{R}\right)$. The values were taken as the average of the last $3 \mathrm{~min}$ of each exercise. The $\mathrm{O}_{2}$ pulse $\left(\dot{\mathrm{V}}_{2} / \mathrm{HR}\right)$ was also calculated for each exercise level. This is equal to the product of the arterial-to-mixed venous $\mathrm{O}_{2}$ content difference and stroke volume. Under conditions where stroke volume can be assumed constant (e.g. upright exercise above $40 \%$ of $\dot{\mathrm{VO}}_{2}$ max) it is proportional to $\mathrm{O}_{2}$ extraction. Recovery HR was measured at 3 and $5 \mathrm{~min}$ after the exercise termination and a blood sample was drawn after 5 min for lactate analysis (1500 Sport, YSI, Yellow Springs, OH).

Statistics: Statistical comparisons to obtain significance of differences $(\mathrm{p}<0.05)$ between measurements during submaximal exercise for smokers and nonsmokers were made with analysis of covariance (ANCOVA) and for specific points and during maximal exercise by ANOVA. Slope differences for lactate were tested for significance with ANCOVA. "Slope" values for comparison of recovery HR between groups were obtained as the first derivative of 2nd-degree polynomial equations fitted to the 3 points for each test.

\section{Results}

The result of the baseline measurements are given in Tables 1 and 2. The $\dot{\mathrm{V}}_{2} \max$ values in $\mathrm{L} / \mathrm{min}$ and $\mathrm{ml} / \mathrm{min} / \mathrm{kg}$ lean body mass were not significantly different $(p=0.12$ and 0.20 , respectively) between the two groups, closely matching those predicted for sedentary and healthy men of the same age, taking into account the higher $\mathrm{VO}_{2}$ max values on treadmill vs. cycle ergometer (Loeppky and Luft, 1989). However, a higher fitness level for nonsmokers was indicated by the significantly lower resting $\mathrm{HR}$ and \% fat and higher $\dot{\mathrm{VO}}_{2}$ max expressed as $\mathrm{ml} / \mathrm{min} / \mathrm{kg}$ wt. The lean body mass did not differ significantly between groups. No significant difference between groups was noted in resting SBP, DBP or exercise HR (Table 2). The $\mathrm{HbCO}$ in smokers was significantly higher by $5.1 \%$. Although 
Table 1 Age, $\mathrm{HbCO}$, wt, \%fat and $\dot{\mathrm{VO}}_{2}$ max of subject groups.

\begin{tabular}{|c|c|c|c|c|c|c|c|c|}
\hline & $\begin{array}{l}\text { Age } \\
\text { (yr) }\end{array}$ & $\begin{array}{c}\mathrm{HbCO} \\
(\%)\end{array}$ & $\begin{array}{c}\mathrm{wt} \\
(\mathrm{kg})\end{array}$ & $\%$ fat & $\begin{array}{c}\text { LBM } \\
(\mathrm{kg})\end{array}$ & $\begin{array}{l}\dot{\mathrm{V}} \mathrm{O}_{2} \max \\
(\mathrm{L} / \mathrm{min})\end{array}$ & $\begin{array}{l}\dot{\mathrm{V}}_{2} \max \\
\text { (per wt) }\end{array}$ & $\begin{array}{c}\dot{\mathrm{VO}}_{2} \text { max } \\
\text { (per LBM) }\end{array}$ \\
\hline \multicolumn{9}{|c|}{ Nonsmokers } \\
\hline $\mathrm{n}-2$ & 34 & 0.35 & 68.7 & 13.9 & 59.2 & 2.86 & 41.6 & 48.3 \\
\hline$n-3$ & 29 & 0.39 & 72.5 & 18.6 & 59.0 & 3.23 & 44.6 & 54.8 \\
\hline$n-4$ & 34 & 0.27 & 76.8 & 18.7 & 62.4 & 4.00 & 52.1 & 64.1 \\
\hline$n-7$ & 40 & 0.41 & 71.9 & 14.3 & 61.6 & 3.88 & 53.9 & 62.9 \\
\hline $\mathrm{n}-8$ & 25 & 0.58 & 63.7 & 14.1 & 54.7 & 3.02 & 47.4 & 55.2 \\
\hline$n-9$ & 22 & 0.26 & 70.3 & 12.7 & 61.4 & 3.35 & 47.7 & 54.6 \\
\hline Mean & 32 & 0.39 & 69.5 & 17.7 & 57.2 & 3.26 & 46.7 & 56.8 \\
\hline SEM & 2 & 0.03 & 1.5 & 1.5 & 1.6 & 0.17 & 1.8 & 2.0 \\
\hline $\mathrm{s}-3$ & 35 & 5.98 & 68.3 & 21.5 & 53.6 & 2.90 & 42.4 & 54.0 \\
\hline $\mathrm{s}-4$ & 33 & 3.44 & 73.4 & 28.9 & 52.2 & 2.80 & 38.1 & 53.6 \\
\hline $\mathrm{s}-5$ & 32 & 4.82 & 65.7 & 19.8 & 52.7 & 2.93 & 44.6 & 55.6 \\
\hline s-6 & 36 & 7.22 & 71.2 & 21.1 & 56.2 & 3.45 & 48.5 & 61.5 \\
\hline s-7 & 30 & 6.69 & 85.9 & 27.8 & 62.0 & 2.77 & 32.3 & 44.7 \\
\hline $\mathrm{s}-8$ & 51 & 3.94 & 78.0 & 30.0 & 54.6 & 2.77 & 35.5 & 50.7 \\
\hline s-9 & 24 & 6.89 & 65.3 & 18.1 & 53.5 & 2.96 & 45.3 & 55.3 \\
\hline Mean & 34 & 5.49 & 73.4 & 24.2 & 55.4 & 2.96 & 40.7 & 53.5 \\
\hline SEM & 2 & 0.44 & 2.2 & 1.4 & 1.0 & 0.07 & 1.7 & 1.5 \\
\hline $\mathrm{p}$-value & 0.65 & $<0.01$ & 0.17 & $<0.01$ & 0.36 & 0.12 & 0.03 & 0.20 \\
\hline
\end{tabular}

$\dot{\mathrm{V}} \mathrm{O}_{2}$ max per wt and per LBM: $\mathrm{ml} / \mathrm{min} / \mathrm{kg}$ $\mathrm{HbCO}$ : carboxyhemoglobin concentration

LBM: lean body mass

Table 2 Mean (1.0 SEM) values for subject groups during rest and maximal exercise.

\begin{tabular}{|c|c|c|c|c|c|c|c|c|c|}
\hline & $\begin{array}{c}\mathrm{HR} \\
(\mathrm{bpm})\end{array}$ & $\begin{array}{c}\text { SBP } \\
(\mathrm{mm} \mathrm{Hg})\end{array}$ & $\begin{array}{c}\mathrm{DBP} \\
(\mathrm{mm} \mathrm{Hg})\end{array}$ & $\begin{array}{c}\mathrm{Hb} \\
(\mathrm{g} / \mathrm{dL})\end{array}$ & $\begin{array}{l}\text { Hct } \\
(\%)\end{array}$ & $\begin{array}{c}\max H R \\
(\mathrm{bpm})\end{array}$ & $\begin{array}{l}\max \dot{\mathrm{V}}_{\mathrm{E}} \\
(\mathrm{L} / \mathrm{min})\end{array}$ & $\max R E R$ & $\max \dot{\mathrm{V}}_{\mathrm{E}} / \dot{\mathrm{V}}_{2}$ \\
\hline \multicolumn{10}{|c|}{ Nonsmokers (9) } \\
\hline Mean & 61 & 120 & 78 & 16.0 & 43.2 & 190 & 111.8 & 1.16 & 34.7 \\
\hline SEM & 3 & 4 & 1 & 0.8 & 1.8 & 2 & 7.4 & 0.01 & 2.3 \\
\hline \multicolumn{10}{|c|}{ Smokers (9) } \\
\hline Mean & 73 & 130 & 79 & 16.6 & 45.9 & 188 & 93.9 & 1.14 & 31.8 \\
\hline SEM & 4 & 6 & 5 & 1.2 & 2.8 & 4 & 4.9 & 0.02 & 1.6 \\
\hline p-value & 0.03 & 0.19 & 0.90 & 0.21 & 0.01 & 0.68 & 0.06 & 0.22 & 0.32 \\
\hline
\end{tabular}

HR: heart rate

SBP: systolic blood pressure

DBP: diastolic blood pressure

Hb: Hemoglobin

Hct: hematocrit

the difference in $\mathrm{Hb}$ concentration and $\mathrm{Hb} / \mathrm{Hct}$ ratio was not significant between groups, the smokers' Hct was significantly higher.

Respiratory responses results to the three sub-maximal and maximal workloads for both groups are shown in Fig. 1. The $\dot{\mathrm{V}}_{\mathrm{E}}$ was similar for the groups at the three sub-maximal runs, but $16 \%$ less for smokers at $\dot{\mathrm{VO}}_{2} \max (\mathrm{p}=0.06)$. Because $\dot{\mathrm{VO}}_{2}$ values in $\mathrm{L} / \mathrm{min}$ at equal percentages of $\mathrm{V}_{2}$ max were lower in 

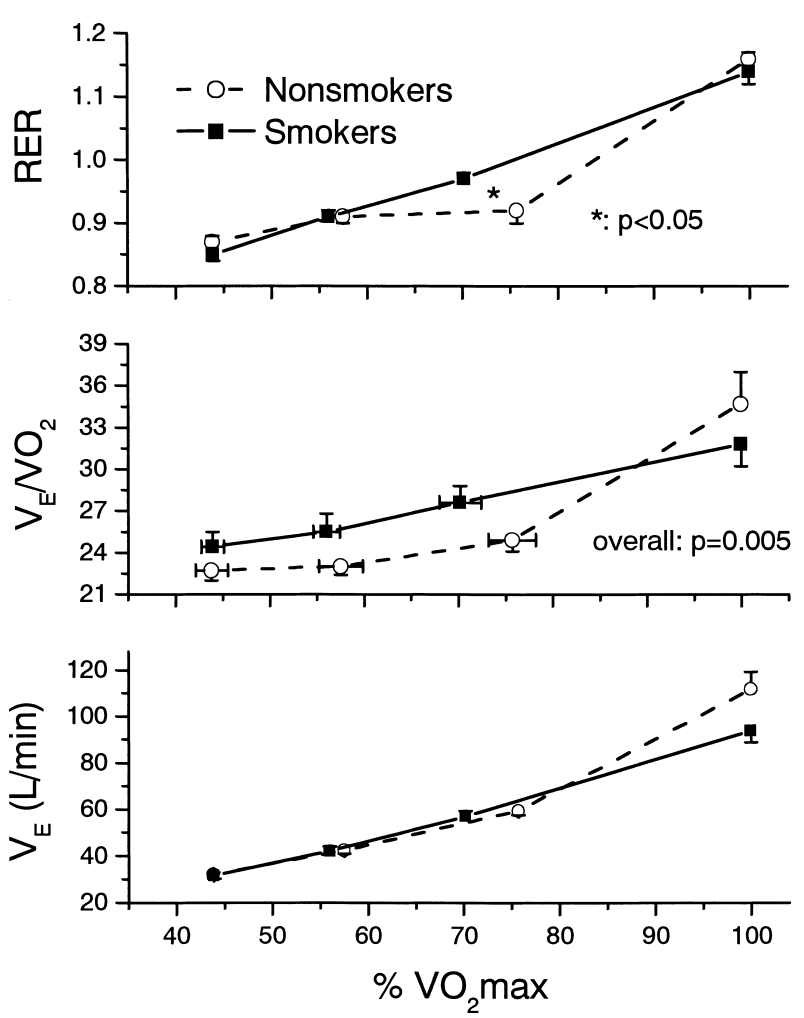

Fig. 1 Pulmonary ventilation $\left(\dot{\mathrm{V}}_{\mathrm{E}}\right)$, ventilation equivalent for $\mathrm{O}_{2}$ $\left(\dot{\mathrm{V}}_{\mathrm{E}} / \mathrm{VO}_{2}\right)$ and respiratory exchange ratio (RER) in 9 smokers and 9 nonsmokers at four exercise levels. Points and bars represent the mean \pm SEM. The mean \pm SEM is also shown for $\%$ of $\dot{V O}_{2}$ max in the middle panel. ANCOVA was used to test the overall difference between smokers and nonsmokers during submaximal exercise levels because $\% \dot{\mathrm{VO}}_{2}$ max values were not identical for the two groups. Overall, the $\dot{V}_{\mathrm{E}}$ and RER values were not different, but the latter was $(\mathrm{p}=0.015)$ by ANOVA for values interpolated at the mean highest submaximal work level (73.2\%).

smokers $\left(-9 \%\right.$ at $100 \%$ of $\dot{\mathrm{VO}}_{2} \max$, see Table 1$)$, the ventilation equivalent for $\mathrm{O}_{2}\left(\dot{\mathrm{V}}_{\mathrm{E}} / \dot{\mathrm{VO}}_{2}\right)$ in smokers was significantly higher by an average of $11 \%$ during sub-maximal work. However, at $100 \%$ of $\dot{\mathrm{V}}_{2}$ max the $\dot{\mathrm{V}}_{\mathrm{E}} / \dot{\mathrm{VO}}_{2}$ ratio was $8 \%$ lower in smokers because $\dot{\mathrm{V}}_{\mathrm{E}}$ was lower. The RER was similar, except at $75 \%$ of $\dot{\mathrm{V}}_{2} \max$, where smokers had a significantly higher value.

The $\mathrm{f}_{\mathrm{R}}$ for the three sub-maximal workloads was $5 \%$ higher, but not significantly, for smokers than nonsmokers and $\mathrm{V}_{\mathrm{T}}$ was increasingly greater in nonsmokers than smokers as workloads increased, but these differences also did not reach significance.

The HR values at the four exercise levels were the same for both groups and are shown in Fig. 2. The $\mathrm{O}_{2}$ pulse averaged $8 \%$ lower for smokers for the four measurements $(\mathrm{p}=0.005)$. The lactate levels were significantly higher for smokers ( $p=0.005$ by ANCOVA over all three workloads) and the rise with workload was steeper for the smokers compared with the nonsmokers $(\mathrm{p}=0.022)$.

The rate of HR recovery after exercise was always slower in smokers (Fig. 3), with "slopes" averaging 43\% higher in
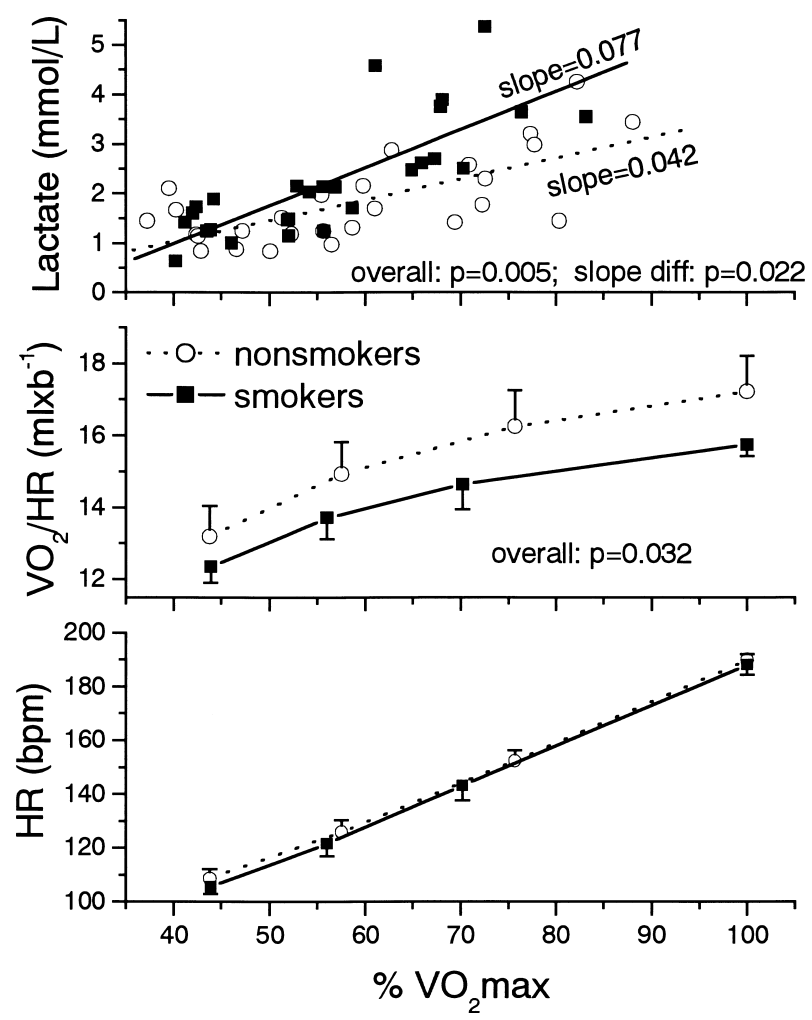

Fig. 2 Exercise $\mathrm{HR}, \mathrm{O}_{2}$ pulse $\left(\mathrm{V}_{2} / \mathrm{HR}\right)$ and venous lactate levels in smokers and nonsmokers. Overall differences between smokers and nonsmokers for lactate and $\mathrm{O}_{2}$ pulse were obtained by ANCOVA, as was the slope difference for lactate. See legend to Fig. 1.

nonsmokers, and this results was significant at each exercise level.

\section{Discussion}

HbCO: Chevalier et al. (1966) reported that the nonsmokers' $\mathrm{HbCO}$ is $<2.0 \%$, depending upon environmental pollutants, while the heavy smoker ( $\geq$ one pack/day) has values $>4.0 \%$. The $5.5 \%$ level in smokers in the present study is greater than the $4.3 \%$ level, previously shown to be the minimal level affecting $\dot{\mathrm{VO}}_{2} \max$ (Horvath et al., 1975). Ekblom and Huot (1972) reported a $9 \%$ reduction in $\dot{\mathrm{V}}_{2}$ max of smokers with a $7 \%$ elevation in $\mathrm{HbCO}$. This suggests that a portion of the $9 \%$ lower $\dot{\mathrm{V}}_{2} \max (\mathrm{L} / \mathrm{min})$ in smokers in the present study can be attributed to $\mathrm{CO}$ binding with $\mathrm{Hb}$ and a reduction in oxygen carrying capacity. At maximal work levels $90 \%$ of the oxygen carrying capacity may be needed (Katz et al., 2000). The 5\% reduction in this capacity by $\mathrm{CO}$ means the muscles' maximal aerobic metabolism is reduced unless the cardiac output is further increased. The similarity of the exercise HR values in the nonsmokers and smokers at equivalent stress levels (Fig. 2) suggests that the cardiovascular system was fully and equally taxed in both groups in terms of stroke volume. This indicates that the arteriovenous difference was smaller and the $\mathrm{O}_{2}$ extraction reduced in smokers. The \%fat was significantly 

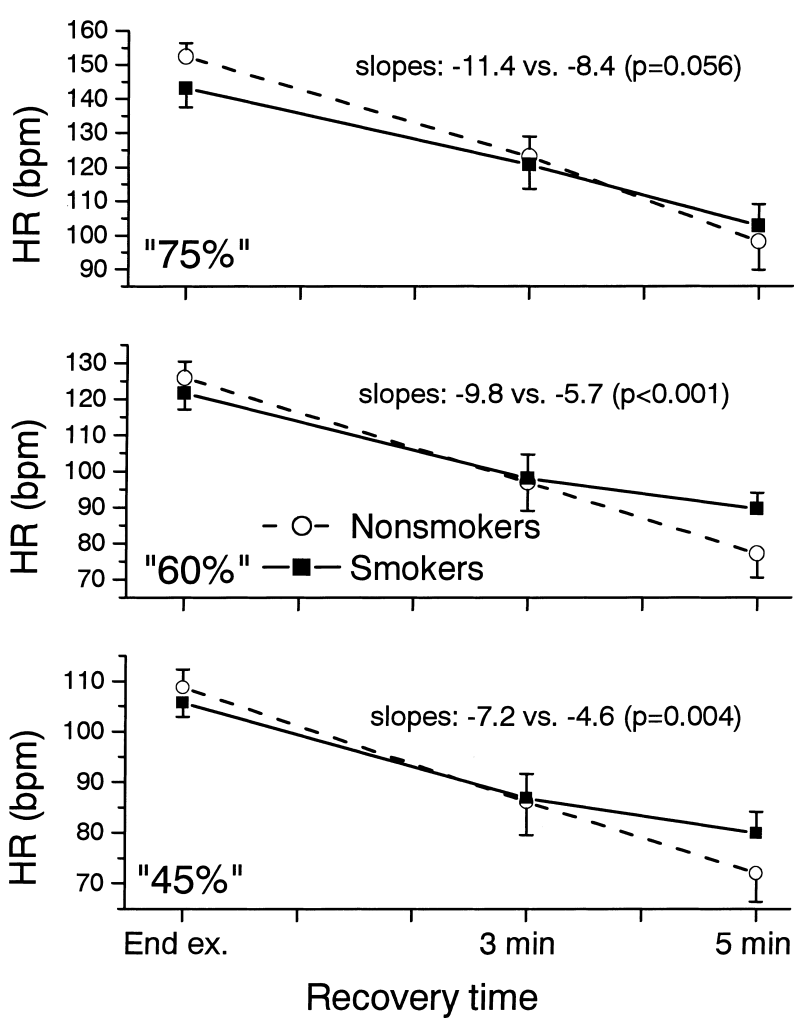

Fig. 3 End-exercise HR and recovery HR at 3 and $5 \mathrm{~min}$ after exercise in smokers and nonsmokers at three levels of exercise. Mean "slope" values are shown. See legend to Fig. 1. Individual "slopes" obtained at $3 \mathrm{~min}$ as first derivative of 2nd-order polynomial fitted to each 3point curve.

greater in smokers than in nonsmokers and contributed to the reduction in aerobic capacity $\left(\dot{\mathrm{VO}}_{2}\right.$ max expressed in $\mathrm{ml} / \mathrm{min} / \mathrm{kg}$ body wt) resulting from elevated $\mathrm{HbCO}$ alone. The increased $\%$ fat in smokers may be related to less regular exercise habits and body weight reduction concerns in smokers.

No significant difference between nonsmokers and smokers was noted in $\mathrm{Hb}$, but Hct was significantly higher in smokers. Polycythemia has been directly associated with the smoking (Van Tiel et al., 2002) and a reduction in plasma volume from nicotine may have contributed to the hemopoietic effect of $\mathrm{HbCO}$ to increase Hct.

Respiratory: During maximal work $\dot{\mathrm{V}}_{\mathrm{E}}$ was higher in nonsmokers than the smokers (Table 2). The reduced maximal $\dot{\mathrm{V}}_{\mathrm{E}}$ in smokers may be related to the chronic effects of smoking on pulmonary function. Another study has demonstrated that $\dot{\mathrm{V}}_{\mathrm{E}}$ was greater during heavy work with $\mathrm{CO}$ (Vogel \& Gleser 1972). However, the $\dot{V}_{E}$ at sub-maximal exercise levels was similar in the two groups in the present study, in agreement with studies by Goldbarg et al. (1971) and Rotstein and Sagiv (1986), with a lower $\dot{\mathrm{VO}}_{2}$ in smokers (Fig. 1) leading to the elevation in $\dot{\mathrm{V}}_{\mathrm{E}} / \dot{\mathrm{VO}}_{2}$. The latter must result from an increase in alveolar deadspace, favoring units with higher ventilation relative to perfusion in the ventilation/perfusion distribution pattern (Hirsch et al., 1985). The smaller $\mathrm{V}_{\mathrm{T}}$ and slightly greater $f_{R}$ in smokers would also contribute to the reduced gas exchange efficiency and gas exchange kinetics (Rotstein et al., 1991).

Circulatory: The effect of nicotine probably contributed to the significantly higher resting HR in smokers (Klausen et al., 1983). Turner and McNicol (1993) also reported significant elevations in HR and blood pressure after nicotine administration. The HR responses of the nonsmokers and smokers to all levels of sub-maximal and maximal exercise were similar (Fig. 2), but the $\mathrm{O}_{2}$ pulse was always lower in smokers (Fig. 3). This has also been reported as an acute effect of smoking (Rotstein et al., 1991). The small difference in $\dot{\mathrm{VO}}_{2} \max (\mathrm{L} / \mathrm{min})$ suggests that cardiac output and stroke volume were also similar throughout, thereby indicating a significant $8 \%$ reduction in tissue $\mathrm{O}_{2}$ extraction in smokers. This may be partially the result of the left shift of the $\mathrm{HbO}_{2}$ dissociation curve induced by $\mathrm{CO}$. Such a shift would reduce $\mathrm{O}_{2}$ unloading at the tissue level for a given capillary $\mathrm{PO}_{2}$ and lead to the apparent reduction of anaerobic threshold. A reduced anaerobic threshold is indicated by the steeper slopes for lactate in smokers in Fig. 2. As a consequence of increased anaerobiosis and reduced tissue $\mathrm{pH}$, an increase in $\mathrm{CO}_{2}$ output via the bicarbonate buffer system would be expected, and is supported by the significantly higher RER in smokers at $75 \%$ of $\dot{\mathrm{VO}}_{2} \mathrm{max}$ (Fig. 2). The failure of RER to remain elevated above nonsmokers at maximal exercise probably reflects the relative insufficiency of maximal $\dot{\mathrm{V}}_{\mathrm{E}}$ in eliminating $\mathrm{CO}_{2}$. Also, increased mismatch of perfusion $(\dot{\mathrm{Q}})$ distribution to working muscles (reduced $\dot{\mathrm{Q}} / \mathrm{V}_{2}$ ) could result in the reduced $\mathrm{O}_{2}$ extraction.

The return of HR to resting levels after exercise was slower in chronic smokers (Fig. 3). This significant reduction in HR recovery must be related to the chronotropic and inotropic effects of catecholamines mobilized by nicotine absorbed from cigarette smoke (Pelican, 1960; Burn, 1987). An animal study by Symons and Stebbins (1996) observed detrimental hemodynamic effects of nicotine on the cardiovascular system at rest, but during exercise these were minimized. These findings were supported by Bolinder et al. (1997) in middleaged men who were long-time users of smokeless tobacco. They found no difference in $\dot{\mathrm{V}}_{2}$ max between these subjects and non-tobacco users, but did find a significant reduction in smokers.

Results from the present study indicate that the habitual cigarette smoking has a significant detrimental effect on cardiorespiratory functions during moderately heavy exercise related to decreased $\mathrm{O}_{2}$ carrying capacity. However, more subtle effects are already apparent at lighter exercise levels in the form of inefficient pulmonary and tissue gas exchange, as manifested by elevated $\dot{\mathrm{V}}_{\mathrm{E}} / \dot{\mathrm{VO}}_{2}$ ratios, reduced $\mathrm{O}_{2}$ pulse values and a slower HR recovery following exercise.

Acknowledgements We express our appreciation to the subjects who volunteered to make this study possible. This research was supported in part by a grant, The Specific Research Promotion, from Chukyo University. 


\section{References}

Bernaards CM, Twisk JWR, Mechelen WV, Snel J, Kemper HCG (2003) A longitudinal study on smoking in relationship to fitness and heart rate response. Med Sci Sports Exerc 35: 793-800

Blair SN, Jacobs DR, Jr, Powel KE (1985) Relationships between exercise or physical activity and other health behaviors. Public Health Rep 100: 172-180

Bolinder G, Noren A, Wahren J, De Faire U (1997) Long-term use of smokeless tobacco and physical performance in middle-aged men. Eur J Clin Invest 27: 427-433

Brozek J, Grande F, Anderson JT, Keys A (1963) Densitometric analysis of body composition: revision of some quantitative assumptions. Ann NY Acad Sci 110: 113-140

Burn JH (1960) Action of nicotine on the heart. Ann NY Acad Sci 90: 70

Chatterjee S, Dey SK, Nag SK (1987) Maximum oxygen uptake capacity of smokers of different age groups. Jpn J Physiol 37: 837-850

Chevalier RB, Krumholz RA, Ross JC (1966) Reaction of nonsmokers to carbon monoxide inhalation: cardiopulmonary responses at rest and during exercise. JAMA 198: 1061-1064

Dauncey MJ (1990) Activity and energy expenditure. Can J Physiol Pharmacol 68: 17-27

Dressendorfer RH, Amsterdam EA, Odland TM (1983) Adolescent smoking and its effect on aerobic exercise tolerance. Phys Sports Med 11: 109-119

Ekblom B, Huot R (1972) Response to submaximal and maximal exercise at different levels of carboxyhemoglobin. Acta Physiol Scand 86: 474-482

Froelicher VF, Jr, Brammell H, Davis G, Noguera I, Stewart A, Lancaster MC (1974) A comparison of the reproducibility and physiological responses to three maximal treadmill protocols. Chest 66: 512-517

Fukuba Y, Takamoto N, Kushima K, Ohtaki M, Kihara H, Tanaka T, Une S, Munaka M (1993) Cigarette Smoking and physical fitness. Ann Physiol Anthropol 12: 195-212

Goldbarg AN, Krone RJ, Resnekov L (1971) Effects of cigarette smoking on hemodynamics at rest and during exercise: normal subjects. Chest 60: 531-536

Hirsch GL, Sue DY, Wasserman K, Robinson TE, Hansen JE (1985) Immediate effects of cigarette smoking on cardiorespiratory responses to exercise. J Appl Physiol 58: 1975-1981

Horvath SM, Raven PB, Dahms TE, Gray DJ (1975) Maximal aerobic capacity at different levels of carboxyhemoglobin. J Appl Physiol 38: 300-303

Katz SD, Maskin C, Jondeau G, Cocke T, Berkowitz R, LeJemtel $\mathrm{T}$ (2000) Near-maximal fractional oxygen extraction by active skeletal muscle in patients with chronic heart failure. J Appl Physiol 88: 2138-2142

Klausen K, Andersen C, Nandrup S (1983) Acute effects of cigarette smoking and inhalation of carbon monoxide during maximal exercise. Eur J Appl Physiol Occup Physiol 51: 371-379

Knapik J, Zoltick J, Rottner HC, Phillips J, Bielenda C, Jones B, Drews F (1993) Relationships between self-reported physical activity and physical fitness in active men. Am J Prev Med 9: 203-208

Loeppky JA, Luft UC (1989) Work capacity, exercise responses and body composition of professional pilots in relation to age. Aviat Space Environ Med 60: 1077-1084

Louie D (2001) The effects if cigarette smoking on cardiopulmonary function and exercise tolerance in teenagers. Can Respir J 8: 289-291

Maksud MG, Baron A (1980) Physiological responses to exercise in chronic cigarette and marijuana users. Eur J Appl Physiol Occup Physiol 43: 127-134

Morton AR, Holmik EV (1985) The effects of cigarette smoking on maximal oxygen consumption and selected physiological responses of elite team sportsmen. Eur J Appl Physiol Occup Physiol 53: 348-352

Park JH, Brown RL, Park CR, Cohn M, Chance B (1988) Energy metabolism of the untrained muscle of elite runners as observed by $31 \mathrm{P}$ magnetic resonance spectroscopy: evidence suggesting a genetic endowment for endurance exercise. Proc Natl Acad Sci USA 85: 8780-8784

Pelican EW (1960) The mechanism of ganglionic blockade produced by nicotine. Ann NY Acad Sci 90: 52

Rotstein A, Sagiv M (1986) Acute effect of cigarette smoking on physiologic response to graded exercise. Int J Sports Med 7: $322-324$

Rotstein A, Sagiv M, Yaniv-Tamir A, Fisher N, Dotan R (1991) Smoking effect on exercise response kinetics of oxygen uptake and related variables. Int J Sports Med 12: 281-284

Symons JD, Stebbins CL (1996) Hemodynamic and regional blood flow responses to nicotine at rest and during exercise. Med Sci Sports Exerc 28: 457-467

Turner JA, McNicol MW (1993) The effects of nicotine and carbon monoxide on exercise performance in normal subjects. Respir Med 87: 427-431

US Public Health Service 1983. The health consequences of smoking - cardiovascular disease: A report of the Surgeon General. US Dept. Health and Human Services. DHHS (DHS) 84-50204, Washington, DC

US Public Health Service 1984. The health consequences of smoking - chronic obstructive lung disease: A report of the Surgeon General. US Dept Health and Human Services. DHHS (PHS) 84-50205, Washington, DC

US Public Health Service 1988. The health consequences of smoking-nicotine addiction: A report of the Surgeon General. US Dept Health and Human Services DHHS (CDC) 88-8406, Washington, DC

Van Tiel E, Peeters PH, Smit HA Nagelkerke NJ, Van Loon AJ, Grobbee DE, Bueno-de-Mesquita HB (2002) Quitting smoking may restore hematological characteristics within 
five years. Ann Epidemiol 12: 378-388

Vogel JA. Gleser MA (1972) Effect of carbon monoxide on oxygen transport during exercise. J Appl Physiol 32: 234-239

Wilmore JH (1969) A simplified method for determination of residual lung volumes. J Appl Physiol 27: 96-100
Received: November 27, 2003

Accepted: August 23, 2004

Correspondence to: Yoshio Kobayashi, PhD The Laboratory for Health and Human Performance, School of Arts and Sciences, Chukyo University, 101-2 Yagoto Hommachi, Showaku, Nagoya 466-8666 Japan

Phone: +81-52-832-2151

Fax: 81-52-835-7183

e-mail: ykobayas@lets.chukyo-u.ac.jp 